French presidential election Good for science?

Champagne corks were popping in science departments throughout France on Monday at the news that François Mitterand, socialist party leader, was to be France's next President. Not that most French scientists are socialists; rather, that science will take a leap forward in France if Mitterand sticks to his announced policies.

Mitterand has promised a "national council for science and culture", reporting to the president, and has announced that spending on research and development in France should reach 2.5 per cent of gross national product by 1985 , compared with the present 1.8 per cent. Mitterand's goal could only be reached with high government spending, for French industry is notably niggardly in its provision for science; Giscard had a more cautious target of 2.3 per cent by 1988 .

The socialist leader has also said he will raise the rank of the minister of science to full cabinet level, so the minister will participate in all major policy decisions. (The current incumbent, Pierre Aigrain, attends cabinet only when matters involving science are under discussion.) Two names are being tipped for the job; François Gros, a biochemist at the Institut Pasteur, who has been active among scientists on Mitterand's behalf; and the career politician Jean-Pierre Chevenement, a member of the chamber of deputies who has taken an interest in scientific affairs. The high level of the post may favour the politician.

Mitterand will also set up a parliamentary special committee for technology assessment, something previously unheard of in France, where technological decisions have been reached in an entirely autocratic manner. The new president is also cool on nuclear power, so France's nuclear lead might be expected to slip unless national pride erodes the president's doubts. He has said he will call for a "pause" in nuclear construction after the reactors now under order, and the fast breeder Super-Phénix, are completed, in order to review the programme.

Robert Walgate

\section{French oceanography}

\section{Pulling together}

The outgoing French government completed the last leg of its reorganization of oceanographic research last month with the creation of a joint interdisciplinary programme between CNRS, which is the main funding body for scientific research, and the Ministry of Universities. The new programme is expected to be in full operation early next year. The reorganization, which began at the end of 1979 when an informal Comité d'Océanologie was set up to advise government, reflects the political importance in
France of technologies for exploiting the mineral and biological wealth of the oceans.

This attempt to coordinate research supportd by CNRS and the Ministry of Universities through the new Programme Interdisciplinaire de Recherche Océanographique (PIRO) is unusual in French research administration, for with the growth of support for oceanography since the Second World War, two disparate research programmes have grown up within the universities and the CNRS laboratories. Although similar difficulties have arisen in other fields, oceanographic research has been particularly affected, according to the director of PIRO, Roger Chesselet.

PIRO's task of coordination will fall to an eighteen-member scientific committee with an annual budget of 11 million FFr, the Ministry of Universities and CNRS each contributing half. The budget, which will be in addition to the 185 million $\mathrm{FFr}$ already spent on oceanographic research,

\section{Bazan protests}

The academic research community in Argentina has been disconcerted by the precipitate sacking of Professor Nicolas Bazan from his posts as Director of the Institute of Biochemical Research at Bahia Blanca and as Professor of Biological Chemistry at the University of the South. Professor Bazan (38) heard of his dismissal only when he returned to Argentina from the United States early in March, but it is held to have taken effect from the end of 1980 .

The most puzzling aspect of this development is that Professor Bazan has insisted that he has no connections with political organizations deemed subversive by the military regime. One explanation is that his success has made him the target for influential jealousy, another that his dismissal is intended as a reminder that the influence of the military persists in the universities of Argentina.

Dr Bazan is a neurochemist who has, in the past few months, been able to demonstrate that in rat models of epilepsy, arachidonic acid and other precursors of prostaglandins are released into the brain in large amounts. Professor Bazan had been planning an investigation of the presence of arachidonic acid in the cerebrospinal fluid of human patients suffering from epilepsy, on the assumption that the underlying cause is a membrane deficiency.

Since his dismissal, Professor Bazan has insisted that he will fight for reinstatement. He has been supported by the staff of his institute, which sent a letter of protest to the President of Argentina on 21 March. The Argentinian press has also covered Bazan's dismissal sympathetically. will be used to run and buy equipment for six small research vessels, and to foster collaboration between several research groups working on different aspects of the same problem. PIRO, whose members are CNRS administrators and oceanographers nominated by CNRS and the Ministry of Universities, will be keen to support fundamental research in physical and biological oceanography, leaving mineral exploration and the application of new technologies to the well-established Centre National pour l'Exploitation des Océans (CNEXO). A small amount of the extra 11 million FFr will, however, be spent on research equipment for use by CNRS and university staff on board CNEXO's large, ocean-going research vessels.

The setting up of PIRO follows the definition of three categories of research: research with short-term application supported by the departments of industry, transport and environment; research with medium- and long-term application supported by CNEXO; and fundamental research, the responsibility of the Ministry of Universities.

Under the new arrangements, the different organizations supporting oceanography will report to the Comité d'Oceánologie. France is also hoping to collaborate internationally, especially with developing countries, on pollution problems and the exploitation of ocean resources when the Law of the Sea becomes operational.

Judy Redfearn

\section{UK university finance}

\section{Truth looms}

British universities should know more clearly next week what the future holds. For then the University Grants Committee will put out a circular spelling out the basis on which recurrent grants will be distributed to individual universities in the next few years. This first circular will be followed in June by more detailed information about the proposed division of the recurrent grant for 1981-82 among individual universities.

The committee has been forced to this two-stage approach by the need for detailed consultation with the Department of Education and Science about ways of sweetening what must certainly be a bitter pill. Originally it had been intended that final allocations would be announced this month. One of the concessions wrung from the government is likely to be an assurance that recurrent funds for the universities will be held for the next three years at the levels suggested in the white paper on public expenditure published in March.

British universities may thus know where they stand more clearly than in recent years, when government support has been determined one year at a time. The promised grants will, in the government's opinion, nevertheless require many universities "to review the range and 